\title{
Chapter 10 \\ LED Lighting Across Borders. Exploring the Plea for Darkness and Value-Sensitive Design with Libbrecht's Comparative Philosophy Model
}

\author{
Els Janssens, Taylor Stone, Xue Yu (D), and Gunter Bombaerts
}

\begin{abstract}
This chapter discusses how a comparative philosophical model can contribute to both substantive and procedural values in energy policy. We discuss the substantive values in the mainstream light-emitting diodes (LEDs) debate and Taylor Stone's alternative plea for darkness. We also explore Value Sensitive Design as a procedural approach. We conclude that the comparative philosophical model of Ulrich Libbrecht can appropriately broaden the set of substantive values used in VSD. We discuss the values of 'by-itself-so' and 'alter-intentionality', which come with the unforeseen necessity of accepting elements from other worldviews and of normativity in the procedural VSD approach.
\end{abstract}

\subsection{Introduction}

Outdoor artificial illumination (often a taken-for-granted backdrop of daily life) is a large consumer of energy. Worldwide, it is estimated that around $19 \%$ of all electricity generated is used for lighting, of which approximately $8 \%$ is used for outdoor stationary lighting (De Almeida et al. 2014). According to the International Energy Agency (2006), there are more than 100 million streetlights alone using around 114 TWh of electricity per year. Thus, how we light our world at night is an

E. Janssens (凹)

School of Comparative Philosophy, Antwerp, Belgium

e-mail: els.janssens@ @libbrechtgenootschap.org

T. Stone

TU Delft, Delft, The Netherlands

$\mathrm{X} . \mathrm{Yu}$

Dalian University of Technology, Dalian, China

G. Bombaerts

TU Eindhoven, Eindhoven, The Netherlands 
important topic for energy ethics, and one that transcends regional or national borders.

The need for an ethical analysis of nighttime lighting comes with additional urgency, as a momentous change to how we light our world at night is underway. In particular, the rapid adoption and proliferation of solid-state lighting, and in particular light-emitting diodes (LEDs), is quickly changing both the technical (and moral) landscape of nighttime lighting. Solid-state lighting offers many technical benefits, including improved colour rendition, longer lifespans, and significantly increased efficacy and efficiency. The controllability of LEDs also makes them suitable for new 'smart' lighting innovations, which uses data collection and monitoring to attune illumination to specific environments and requirements. The combination of these two innovations_-LEDs and smart lighting — offers the potential for massive energy savings. For example, a report by the US National Academy of Sciences (NAS 2017) estimates that if LEDs reach their target efficacy of $200 \mathrm{~lm} / \mathrm{W}$ by 2025 , it could result in up to $40 \%$ savings on energy consumed for lighting by 2030 . De Almeida et al. (2014: 45) similarly highlight the potential energy savings in the EU by 2030, stating, 'The estimated savings potential through the application of LED lighting systems in the EU is around 209TWh, which translates into 77Mt of CO2. The economic benefits translate into the equivalent annual electrical output of about 26 large power plants (1000MW electric), with the value of 30 billion Euros of saved electricity costs assuming an average price of $0.15 € / \mathrm{kWh}$.

Given the efficiency and projected cost-effectiveness of (smart) LED lighting, there has been a rapidly increasing adoption in the domain of outdoor illumination, with major cities across the world undertaking (smart) LED retrofit projects for their public spaces. However, despite the promises of smart LED streetlights, the full range of impacts is still emerging. The effects on human and ecosystem health, and if they will further diminish experiences of the night sky, are being debated and researched. Further, whether or not they actually deliver on the promised energy savings has been called into question. Taking a pragmatic perspective, we can see these concerns as highlighting a need to understand how this new technology can, and should, be implemented.

In this chapter, we analyse how a particular comparative philosophical model can contribute to both substantive and procedural values in debates about the adoption and use of LEDs. To discuss substantive values, we focus on the strengths and challenges of an alternative set of values centred on a 'plea for darkness' in the LED debate (Stone 2018a, b). We also look at procedural values in the LED debate, taking Value-Sensitive Design (VSD) as an example. VSD represents a proactive method to consider the values of all relevant stakeholders throughout the process of technology design. The basic idea is that VSD can help in analysing how a particular technology design conditions particular behaviour, attitudes and worldviews. In line with the aspirations of this edited volume, we apply the comparative philosophical model to the substantive plea for darkness discussion and the procedural VSD approach.

We opt for the comparative philosophical model of Ulrich Libbrecht, which describes worldviews from three fundamentally different perspectives (we will call 
this ideal types later on): immanentism, rational transcendence and emotional transcendence. We argue that a classical VSD approach to smart LED lights risks focusing on a standard list of values in keeping with only one of these worldviews, such as control, efficiency and comfort. A focus on the other ways of thinking will bring in very different values. We conclude that Libbrecht's model broadens the set of values used in the LED debate, and that this comes with the unforeseen necessity of accepting elements from other worldviews and of normativity in the procedural VSD approach.

\subsection{Substantive Values in the LED Lighting Debate: A Plea for Darkness}

While industry, municipal governments, and some researchers have been enthusiastic proponents of LEDs for outdoor lighting, other scholars take a more cautionary approach, and point to a wider set of values that have to be balanced.

Interestingly, the development and adoption of LED outdoor lighting is occurring at the same time as another evaluative shift in nighttime illumination caused by a growing recognition of its negative effects, commonly categorised as 'light pollution'. Artificial nighttime lighting costs (and arguably wastes) billions of dollars annually, uses large amounts of energy, affects human health, disrupts wildlife and ecosystems, and following this argument, hinders our experience of a starry night sky (see Stone 2017, 2018b). LED lighting is often championed as a cost-effective solution to the emergent problems of light pollution. However, current retrofit strategies-while offering lower costs and energy efficiency-are expected to exasperate many adverse effects of light pollution. For example, the blue-rich lighting may further impact human health by disrupting our circadian rhythms, and has been linked to health problems such as insomnia, obesity, and even certain types of cancer (AMA 2016; Chepesiuk 2009). Further, early research indicates that neither energy usage nor skyglow (a form of light pollution that is particularly detrimental to the visibility of the night sky) has decreased alongside the adoption of LEDs (Kyba et al. 2017).

A clarification of the conceptual dimensions of the LED transition, and in particular how 'environmental' value is defined, is thus needed. Proponents of LEDs often say that it is a 'green' technology. This is primarily because of their efficiency and contributions to energy reductions, as well as other issues such as a longer life cycle, lower maintenance requirements and their avoidance of mercury, amongst other factors. Thus, a largely technical definition of sustainability is applied. However, criticisms of the widespread adoption of (especially blue-rich or whitecoloured light) LEDs for outdoor lighting by the public, as well as prominent voices such as the International Dark-Sky Association and the American Medical Association, suggest that a broader, more comprehensive analysis of the values at stake would improve the moral and social acceptability of this new technology. 
To explore values relevant to the LED transition, we take a critical look at the recent work by Stone (2017, 2018a, b, 2019). In particular, we examine Stone's 'The Value of Darkness: A Moral Framework for Urban Nighttime Lighting' (2018b), which explores the landscape of environmental values relevant to nighttime lighting. Stone argues for a shift away from avoiding or mitigating light pollution, instead moving towards a recognition and maximisation of the positive features of darkness. Darkness has long been associated with largely negative values and is often associated with danger or risk (e.g. Nye 1990; Schivelbusch 1988), leading us to seek out solutions via control and dominance over these threats. Darkness is also seen to be backwards, in opposition to the progress and innovation brought about by artificial illumination. Cities characterise themselves by their illuminated skyline, not by their darkness, for instance. Indeed, through the development and proliferation of lighting technologies, we have effectively conquered the night (Melbin 1987). The (urban) night has become a prolongation of the day due to the proliferation of electric lighting.

In 'The Value of Darkness' (2018b), Stone proposes a set of environmental values meant to reflect the changing landscape of moral evaluations brought about by a growing recognition of the negative impacts of artificial light at night. Firstly, he states that efficiency and sustainability are important values for darkness. He refers to Gallaway et al. (2010), stating that $30 \%$ of light in the U.S. is wasted (equivalent to a yearly loss of almost $\$ 7$ billion in U.S.), as well as to Morgan-Taylor's (2014) similar estimate of $€ 5$ billion in Europe. Stone also mentions that darkness may be beneficial for healthiness and happiness, for example, by following the biorhythm and focusing on experience compared to consumption. Stone classifies these values as instrumental because darkness here is a means to achieve another end.

But Stone also sees intrinsic values in darkness. Darkness is useful for the conservation of species and biodiversity. Contact with nature is also an intrinsic value central to environmental philosophy, which is argued to be a central facet of dark or 'natural' nights. Further, the visibility of the starry sky and wonder and beauty are intrinsic values linked to darkness. Lastly, he states that the loss of darkness also includes the loss of cultural heritage. Overall, this discussion indicates a clear need to clarify LED applications' strengths and weaknesses, and to critically examine the policy choices shaping the use of this new lighting technology.

\subsection{Procedural Values in the LED Lighting Debate: Value-Sensitive Design}

As we want to explore the procedural aspects of the LED lighting debate, we can analyse a variety of participation methods (see, for example, Rowe and Frewer 2000; Laes and Bombaerts 2006) to better understand the interplay between the need for participation and the quality of procedures. In the limitation of this chapter, we concentrate on one example. We focus on Value Sensitive Design (VSD) as a 
validated and widely used methodology to implement values in such design processes. As said earlier, VSD represents a proactive method to consider the values of all relevant stakeholders throughout the process of technology design. The basic idea is that VSD can help in analysing how a particular technology design conditions particular behaviour, attitudes and worldviews.

The practice of VSD is characterised by a diversity of approaches, theoretical backgrounds, application domains and values for which it is designed. The VSD core is an iterative, tripartite methodology including the results of conceptual, empirical and technological investigations. The conceptual part maps the relevant stakeholders, their values and the value conflicts in the innovation process and the use of the new technology. As such, VSD enables relevant stakeholders to balance a multitude of values such as well-being (Brey 2015), accountability and transparency (Hulstijn and Burgemeestre 2014), democracy and justice (Pols and Spahn 2015), inclusiveness (Keates 2015), privacy (Warnier et al. 2015), trust (Nickel 2015) and responsibility (Royakkers and Orbons 2015). The empirical part qualitatively and quantitatively studies the interaction between design aspects in relation to stakeholders' understandings and experiences of technology. The technical part then primarily studies how specific technology features implicate certain values. Technical investigations can involve either analysis of how people use related technologies, or the design of systems to support values identified in the conceptual and empirical investigations (Friedman et al. 2013).

The original VSD scholars legitimise their method with regard to Habermassian communicative action: 'In communicative action, each utterance implicitly raises four validity claims: to the comprehensibility of the utterance, to the truth of its propositional content, to the truthfulness of the expression of the speaker's intent, and to the rightness and appropriateness of the utterance with respect to existing norms and values' (Borning et al. 2005: 454). Thus, VSD can treat a broad spectrum of values. However, one of the challenges of VSD is exactly which values are treated (Davis and Nathan 2015). The answer largely depends on the initiators of the process, the guardians of the process and the stakeholders present. Some values might be lacking, for instance, leading to unforeseen consequences or even non-acceptance in the end of the process. As such, we seek an approach that enables VSD to discuss a list of values that is practical enough to use, but also covers a range of values that is wide enough.

Stone's work on the value of darkness can be understood as satisfying the conceptual step in the VSD methodology. It strives to establish the philosophical grounds for incorporating environmental values into lighting technologies and policies, as well as to synthesise and categorise current research and arguments made for the protection and preservation of 'natural' nights. However, when looking towards the operationalisation of Stone's framework for the LED transition (i.e. the technical implementation stage of VSD research), important conceptual questions arise.

We can ask if the LED lighting debate as pictured above is analysed broadly enough. Should environmental values, for example, be disentangled from social values associated with lighting and darkness in a VSD process? Stone's plea seems 
to clash with fundamental economic values that are ubiquitous in technology debates, such as how far do we want to limit 24-h economic activity, or what we are willing to sacrifice to allow for access to a starry sky? And do we want to sacrificeeven only a little bit—of our safety and security? ${ }^{1}$

Moreover, is the identified valuableness of darkness proposed by Stone reliant on a particular dominant perspective that is not shared by all people? The nine identified environmental values associated with darkness are presented in a somewhat descriptive way. They are presented as things that, in general, people value, and are thus important considerations, without identifying or arguing for an underlying ontological or meta-ethical basis for the worthiness of the values. This in turn can lead to practical questions of 'if' and 'how' the 'designing for darkness' approach proposed by Stone elsewhere (Stone 2019) can manifest in different cultural, political, and geographical contexts. As such, the question becomes if, and how, a 'LED transition debate across borders' is possible.

Our reflection so far raises questions about the fundamental principles of VSD methodology. In broadening the set of values from environmental to also societal and deepening the discussion to underlying values, the role of VSD facilitators might change. Instead of bringing up and mapping the relevant values in a neutral way, the role now seems to shift more to steering the debate towards 'Value Sensitive Design across borders'.

\subsection{Ulrich Libbrecht's Comparative Philosophy Model}

\subsubsection{The Overall Model}

In the above sections, we listed the substantive challenges we encountered in the plea for darkness and the procedural ones we faced in the VSD discussion. In the frame of this volume, we will now explore how a comparative philosophical model can answer these questions. We utilise Ulrich Libbrecht's comparative philosophy model, which starts from an analysis of three different philosophical perspectives based on three fundamentally different sets of assumptions and tries to integrate them in one model. Libbrecht calls these sets of coherent assumptions worldviews. By considering three fundamental worldviews, it deals with complexity when looking for underlying structures, but it is also manageable and operational. As such, the model itself provides integration and distinguishes itself from a universalism that looks for one main super-value that unites everyone's main striving. Its description also avoids the over-complexity of pluralism as an irreducible and incommensurable set of different opinions. 'As citizen of the world I am trying to integrate them [the three different worldviews], not into a kind of sameness, but into a global model that admits dialogue' (Libbrecht 2007: 71).

The three basic worldviews can be described by different elaborations of the philosophical concepts immanence and transcendence (for a graphical view, see 
Fig. 12.1 in Oostveen in this Volume). Libbrecht considers nature as the immanent basis (immanere $=$ to remain within) that can be transcended (transcendere $=$ to rise above, to exceed) by culture, science and technology. Therefore, every philosophical elaboration on humans, world and technology will have to relate to both nature and culture. But their implicit assumptions how to focus on happiness, harmony, truth, or wisdom clearly differ. The more immanent focused worldviews strive mainly for the direct experience of nature and of the natural processes themselves. Transcendent worldviews emphasise to exceed and overcome the direct experience of nature and of the natural processes. Libbrecht states that this transcendence can be achieved in mainly two different ways. Humans can use rationality to understand nature with science and control it by using technology. This rational transcendence focuses on knowledge and empirical experimentation to find the truth. But humans can also develop an emotional transcendence, giving attention to the inner experience of the unity of humans and nature and to exceed the natural ego. Libbrecht (2007: 122-3) calls this focus 'alter-intentionality': 'When I reveal myself emotionally to the Other, it induces in me a certain mood, puts me in an emotional state, yet one that does not appropriate. I am prepared to undergo feelings of displeasure to have an experience of the Mystery'.

Technology can be seen as a direct consequence of rational transcendence (Feenberg 2012; Misa et al. 2004), but Libbrecht also considers technology as a condition for emotional transcendence. Technology ensures that humans can liberate themselves from the natural struggle for life, which creates room for other emotions such as poignancy, wonder and compassion. Technology can also transfer many tasks, liberating time to focus on other things if the free time is not filled in right away with other practical tasks or addiction ( $\mathrm{O}^{\prime}$ Keeffe and Clarke-Pearson 2011). Therefore, technology has to preserve its middle position and be conscious of its value in the development of other values beyond anything purely scientific and technological. Therefore, technology is also important in immanence-oriented worldviews because technology should be restricted and guided by nature, which can be called 'guiding technology by Dao' (以道驭术). This immanent idea indicates that technology itself should be 'good', meaning that human-made technology respects the inherent qualities of nature (Wang and Zhu 2011).

Based on these three basic worldviews, Libbrecht sees three basic relations between humans (Subject) and the world (Object). First, in the purely immanent worldview, the subject is an organic part of the object because the body directly participates to the natural processes and rhythms. The object informs the subject by direct experience. Libbrecht indicates this with the mathematical relation $\mathrm{S} \subset \mathrm{O}$, the subject is ego-intentional. Secondly, in rational transcendence, the subject opposes the object. This is its rationality. The subject places herself at a rational distance against reality. She develops scientific insights and technology with which she transcends, controls and redirects the natural given. This is indicated by $\mathrm{S} \leftrightarrow \mathrm{O}$. Thirdly, in the emotional transcendence, the subject becomes one with the object. The subject is in inner experiential relation with the entire reality. This is described by $\mathrm{S}=\mathrm{O}$ and the subject is basically alter-intentional. 
These three perspectives in their purest forms do never appear in reality. Libbrecht therefore calls them ideal types (2009: 32). In the remainder of this chapter, we often simply refer to these ideal types of worldviews as worldviews. However, every worldview in the real world is a non-clearly distinguishable combination of the three perspectives described above. It is therefore relevant to study the ideal types as they constitute worldviews in the real world. Some worldviews are strongly oriented to one of the three ideal types. Following Libbrecht $(2007,95)$, we then talk about (for example) immanence-oriented worldviews.

Every worldview is a coherent set of different elements that help to interpret concepts of being (ontological), knowledge (epistemological), humans (anthropological), but also how the concepts of time, space, causality, ethics and language are used (Libbrecht 2009: 36-37). Below, we explain the ideal types in more detail as a coherent set of different element. An overview of these different elements per worldview can be found in Table 10.1.

Table 10.1 Overview of the worldview elements of immanentism, rational transcendence and transcendent emotionality, taken from Libbrecht (2007: 290), except from lines in italic of 'Value determination(s)' and 'Technologies', which are the author's

\begin{tabular}{|c|c|c|c|}
\hline $\begin{array}{l}\text { Basic relations } \rightarrow \\
\text { // Different } \\
\text { worldview } \\
\text { elements } \downarrow\end{array}$ & $\mathrm{S} \subset \mathrm{O}$ & $\mathrm{S} \leftrightarrow \mathrm{O}$ & $\mathrm{S}=\mathrm{O}$ \\
\hline Worldviews & Immanentism & Rational transcendence & $\begin{array}{l}\text { Emotional } \\
\text { transcendence }\end{array}$ \\
\hline Energy & Bound & Free, goal-oriented & Free, field of action \\
\hline $\begin{array}{l}\text { Value } \\
\text { determinations }\end{array}$ & $\begin{array}{l}\text { By-itself-so, non- } \\
\text { action, humans } \\
\text { as part of nature }\end{array}$ & $\begin{array}{l}\text { Rational insight, } \\
\text { control and comfort }\end{array}$ & $\begin{array}{l}\text { Alter-intentionality, } \\
\text { compassion, awareness, } \\
\text { equanimity }\end{array}$ \\
\hline Ontology & Becoming & Being & Non-being \\
\hline $\begin{array}{l}\text { Epistemology, } \\
\text { methodologies }\end{array}$ & Direct experience & $\begin{array}{l}\text { Rational knowledge } \\
\text { and empirical } \\
\text { observation, logic }\end{array}$ & $\begin{array}{l}\text { Internal experience } \\
\text { Mysticity, authenticity }\end{array}$ \\
\hline View on humans & Body & Rational function & Emotional function \\
\hline Time & Cyclic & Linear & Timeless \\
\hline Space & Ecological & Mathematical & Mystical field \\
\hline Causality & Reticular & Linear/binary & Field \\
\hline Ethics & $\begin{array}{l}\text { Confidence in } \\
\text { by-itself-so, } \\
\text { non-action }\end{array}$ & Legalism-justification & Love, compassion \\
\hline Language & Metaphoric & Logic/mathematic & Symbolic/silence \\
\hline Technologies & $\begin{array}{l}\text { Attuned to and } \\
\text { subordinate to the } \\
\text { natural process }\end{array}$ & $\begin{array}{l}\text { Control of natural } \\
\text { processes, comfort of } \\
\text { man }\end{array}$ & $\begin{array}{l}\text { Facilitating } \\
\text { alter-intentionality }\end{array}$ \\
\hline
\end{tabular}




\subsection{2 $S \subset O$ : Humans as Part of Nature}

Firstly, nature-focused worldviews start from the basic relation $\mathrm{S} \subset \mathrm{O}$. The subject $(\mathrm{S})$ feels embedded $(\subset)$ in the surroundings or world $(\mathrm{O}=$ object $)$. These immanent philosophies are cosmocentric and see humans as very small and timely parts of the whole cosmic process.

Immanence-oriented worldviews can be found all over the globe. Libbrecht (2007: 550-572) refers to several examples such as traditional native American worldviews, Daoism, Japanese Shintoism, Sub-Saharan Africa philosophies, forms of nature mysticism and pantheism, and Buddhist philosophers such as twentiethcentury's Nishida. Although they were mostly peripheral, some Western philosophies that stress natural becoming such as Stoa, Heraclitus, Nietzsche, Whitehead or Bergson, or that stress pantheism such as Spinoza can also be considered as philosophies that carry a strong immanent element.

The main value of immanent philosophies is nature itself. The traditional Chinese word for nature自然 (ziran) means 'by itself so' or 'the way things are'. Every part of nature — a blade of grass, bird or planet—moves without human beings or gods. It moves in interaction with the whole reticulum or network embedded in the ecological space. This large cosmic process in which everything including man, arises and passes away is the great wonder and therefore sacral. It is the basis for value creation, what happens by itself so (Dao 道 or 'way' in Daoism) is more precious compared than what is added by human beings. 'Becoming' can be experienced in every part of nature and is expressed in metaphoric language borrowed from nature itself.

Acting does not start consciously from an individual purpose, but everything happens starting from the organic network (reticular). This makes nature ethically indifferent. Nature is neither good nor bad. Life and death or day and night are considered inherent to the natural process. Death and night therefore are not considered as bad, but a necessary condition for the totality. Time in this view is inherently cyclic as it expresses the arising and passing away of everything. 'Body' is seen as the crucial aspect of man. This body maintains itself by reacting to the surroundings with its adaptive phylogenetic knowledge that it inherently holds. The $\mathrm{S} \subset \mathrm{O}$ relation also implies that the subject is always embedded in a group or community. Although life is strongly determined by survival, it is not the individual survival, but the survival of the group or the cosmos one is included in.

As human beings have freedom, the need for ethics emerges (Libbrecht 2007: 98). Being attuned to natural rhythms and bodily processes does not need external rules or ethics. Humans only need to keep watching over the natural process to be attuned to themselves. Daoism grasps this with the concept of non-action (wu-wei 无为), meaning not disturb the natural way. This is of course an idealised state, since we cannot live without transcendence. But immanentists as the Daoists believe we should always be critical to every form of innovation and progress and we should reduce our technological interventions to a minimum. Progress will eventually bring us in a permanent state of agitation (Libbrecht 2007: 154). Progress is also superfluous, in that the most important things happen by themselves. 
Also other scholars referred to wu-wei. Yu and Wang (2015), for example, write about the 'unity of humans and nature', which signifies humans and nature being integrated into an organic unity, has prevailed from ancient China. Being a valuable gift born out of nature, mankind should awe and respect nature, and obey the natural law. Other than protecting itself, nature has the ability to bless human beings reproducing themselves, so that there is no need to take the ethical responsibility of protecting nature. Within the idea of 'unity of humans and nature', specific technical activities should 'conform to both natural law and human nature'(顺天应人), and be restricted and guided by 'Dao', so as to meet the standard of 'Dao'. Tracing back to pre-Qin times, Confucianism proposed 'sponsoring heaven and earth for gestation' (赞天地之化育). The word 'sponsor'(赞) indicated that human technical activities should be in accord with natural law to 'sponsor' transforming and nourishing powers of Heaven and Earth. In doing so, technology will benefit the survival and development of mankind so that 'one could own the powers of the Universe'(与 天地相参). The concept of 'non-action'(无为), being understood as no unnatural action rather than as being complete passivity, implies that mankind should take appropriate action in accordance with the true nature of the universe, complying with the law of development of the universe, so as to realise 'Dao's consistency of human with nature'(道法自然).

There is an important difference if the justification of LED technology had or has no immanence issues. We will come back to this in the discussion, but as an illustration here, we can already say that a justification on LED lighting with little immanent elements is often missing the inherent value of nature and has difficulty doing justice to direct experience. For justifications to be immanence focused, they have to be cyclic, reticular and metaphoric in their approach and are quite different from other approaches. A fruitful interaction therefore demands awareness of these aspects and a strong willingness to bridge the different worldviews.

\subsubsection{S↔O: Humans Opposed to Nature}

In 'Greek philosophy — with the exception of Heraclitus and the Stoics—' we see 'a struggle against becoming, driven by the idea that the everlasting is the perfect' (Libbrecht 2009: 48). This resulted in dualistic theories about eternally lasting elements of 'being': Empedocles' theory of the four elements, Parmenides' theory of being, Democritus' theory of atoms, Plato's theory of ideas and Aristotle's unmoved mover, are all concepts of everlasting elements transcending natural becoming, for instance. Libbrecht gives more examples in summarising the fundamental items in the Greek classical worldview (2007: 244-245). Further, he claims: 'To me, the Islamic and Jewish (next to the Christian) philosophies are highly tributary to Greek thought' (2009: 32). 'They believe in the existence of Being as such, i.e. in the Absolute, which is mostly conceived as unchanging, everlasting' (2007: 389). According to Libbrecht, the desacralising of nature and cosmos starts in Greek 
thought (2007: 244) and is perpetuated in the theontic traditions (Judaism, Christianity, Islam) (2007: 554-556).

The basis of Western transcendent rationality starts with Parmenides who stated that the real reality is linked with what can be thought and is continued by Hegel's idea that the real reality is rational (Libbrecht 2007: 158). Indian Hinduist philosophies have known this as well, although peripherally. The atomic pluralism of the Vaifeșika and the systematic development of logic of the Nyāya are examples hereof, although they remain embedded in a spiritual context focused on spiritual redemption (Libbrecht et al. 2016: 60). Chinese philosophies have always been very pragmatic, but seldom purely rational $(\mathrm{S} \leftrightarrow \mathrm{O})$ because of their fundamental premise that humans are part of nature $(\mathrm{S} \subset \mathrm{O})$.

In sciences, the dynamic fluid of the world of becoming is captured in theories, formulas and definitions by experiment and directed observation. Experimental science projects reality to a mathematical space and disaggregates causal relations as much as possible to binary parts expressed in logic and mathematical language. It deduces the natural rhythm of time into a linear time that is mathematically divided into equal parts. Human beings add new artefacts into reality, make the outside world controllable and contribute to man's comfort as central endeavour. The division $\mathrm{S} \leftrightarrow \mathrm{O}$ is often seen as a core necessity of objectivity in classical scientific methodology (although there is a large observer effect debate on this since the start of quantum physics).

Rationality also has a crucial role in ethics. According to Greek philosophy, reason realises goodness and reason is the basis for laws and prescriptions that arrange human coexistence. Moreover, in the theontic religions, goodness and charity are pursued by adhering to the laws of the god. In Chinese philosophy, this ethical approach also occurred in fă jiā 法家 (Legalism) aiming at orderly coexistence by subjugating to laws, whereas other Chinese philosophies strive for goodness more by emotional development, as Confucianism by $l i$, 礼.

A rational transcendence worldview optimises rational knowledge, empirical observation and logic. It is linear, binary and focuses on control of natural processes in the comfort of man. It is at the basis of the tremendous technological progress. But from within this worldview, it is difficult to understand and accept the implicit value of nature and the value of direct experience as we sketched in the immanence worldview. This worldview also has difficulties to provide a justification for internal experience, emotions, silence and compassion. These important human aspects are core of a third worldview that we will sketch in the next part.

\subsection{4 $S=O$ : The Unity of Humans and Nature}

Thirdly, we elaborate on the transcendent emotionality worldview. This worldview takes $\mathrm{S}=\mathrm{O}$ as its basic relation, which is part of philosophies that postulate the fundamental unity of all what is. It is central to mystical traditions as Buddhism, Sufism, Advaita Vedanta and Meister Eckhart. This transcendent emotionality can 
also be found in the theories of the One of Plotinus, of Friedrich Schelling's energy concept that later was taken by Schopenhauer and Nietzsche, of the Irish John Scottus Eriugena and of Baruch Spinoza. Although this monist theory is present in the entire Western philosophy, it remains peripheral, contrary to the Asian traditions taking fundamental unity as a basic assumption. These traditions also focus on experiencing unity instead of thinking it as the European counterparts do.

The whole can neither be observed nor approached by reason. Via yoga and meditation, a direct, immediate and intuitive vision of reality is experienced. The $\mathrm{S}=\mathrm{O}$ relation is an inner experience relation. It is important to state that the name 'emotionalism' does not refer to a classical Western concept of 'emotions', but to this immediate and intuitive vision of reality in which the ego disappears in alter-intentionality.

When someone wants to express or reflect on the experience, the relation immediately becomes $\mathrm{S} \leftrightarrow \mathrm{O}$. Therefore, silence is an important feature and language can only be symbolic. The relation is mystic and focuses on non-being (nonconceptualisation) and timelessness. This view does not deny existence but denies the conceptualisation of the fundament of existence. Libbrecht uses the metaphor of an electromagnetic field to describe the inner movement of oneness. The cause is not visible; we can only determine it because it moves things, in this case the inner life of persons. For transcendent emotionalists, the coherence is caused by a mystic field. Reality is considered as fundamentally not knowable (Libbrecht (2007: 129) calls this "mysticity"). Transcendent emotionalists accept that science can provide knowledge on all observable things, but that scientific knowledge by definition always will face the boundaries of the unknowable.

We are not separated individuals, but unified with everything in reality. In Buddhism, this leads to the principle of ahimsa (nonviolence). Ethical values are compassion (karuñā), sympathetic joy (muditā), friendliness (maitrī), awareness (smriti) and equanimity (upekshā) (Kalupahana 1995: 61). Contrary to legalistic ethics, love in Buddhism is not a law, but a spontaneous emergence stemming from developing emotionality. Central in ethics is the approach of intentionality. Is ethical behaviour focused on the wholeness and alter-intentionality or does one's egointentionally break the totality apart into several individuals?

One can ask how technological developments incite users to ego- or alterintentionality and how much the individual parts or the totality. As mentioned earlier, technology can be beneficial to create room for the development of transcendent emotionality, but it can also create extra hindrances.

The transcendent emotionality worldview is strongly aware of the importance of compassion, equanimity, internal experience, emotion, compassion and silence. It is at the basis of a rich internal life. But from within this worldview, it is difficult to provide a justification to solve human problems with technology or focus on the direct experience as we sketched in the immanence worldview. Thirdly, we elaborate on the emotional transcendence-oriented worldviews. These worldviews take $\mathrm{S}=\mathrm{O}$ as its basic relation, which are part of philosophies that postulate the fundamental unity of all what is. 'It was already assumed at the time of the Upanishads that there were two levels of reality: on the one hand the empirical multiplicity of our observable world, and on the other the universal oneness' (2007: 258). Further, 
Libbrecht states that this is an assumption in every philosophy that has a mystical dimension. He finds this mystical dimension in traditions around the globe (2016) as Buddhism, Sufism, Advaita Vedanta and Western mystics (2007: 160). This idea of fundamental oneness can also be found in the theories of the One of Plotinus, of Friedrich Schelling's energy concept that later was taken by Schopenhauer and Nietzsche, of the Irish John Scottus Eriugena and of Baruch Spinoza. Although this monist theory is present in the entire Western philosophy, it remains peripheral, whereas in several Indian and Japanese philosophies, this became a central point. These traditions also focus on experiencing unity instead of thinking unity as the European counterparts do.

The whole can neither be observed nor approached by reason. The $\mathrm{S}=\mathrm{O}$ relation is an inner experience relation. It is important to state that the name 'emotionalism' does not refer to a classical Western concept of 'emotions', but to this immediate and intuitive vision of reality in which the ego disappears in alter-intentionality. The twentieth-century Japanese philosopher Nishida describes this as a pure experience: 'When one directly experience one's own state of consciousness, there is not yet a subject or an object, and knowing and its object are completely unified' (1990: 3-4).

When someone wants to express or reflect on the experience, the relation immediately becomes $\mathrm{S} \leftrightarrow \mathrm{O}$, because reflection requires distance. Therefore, silence is an important feature and language can only be symbolic. The relation is mystic and focuses on non-being (non-conceptualisation) and timelessness. This view does not deny existence, but denies the conceptualisation of the fundament of existence. Libbrecht uses the metaphor of an electromagnetic field to describe the inner movement of oneness. The cause is not visible; we can only determine it because it moves things, in this case, the inner life of persons. For emotionally transcendentalists, the coherence is caused by a mystic field. Reality is considered as fundamentally not knowable (mysticity). Transcendent emotionalists accept that science can provide knowledge on all observable things, but that scientific knowledge by definition always will face the boundaries of the unknowable.

We are not separated individuals, but unified with everything in reality. In Buddhism, this leads to the principle of ahimsa (nonviolence). Ethical values are compassion (karuñā), sympathetic joy (muditā), friendliness (maitrī) and equanimity (upekshā) (Kalupahana 1995: 61). Contrary to legalistic ethics, love can also be a spontaneous emergence stemming from developing emotionality. Central in ethics is the approach of intentionality. Is ethical behaviour focused on the wholeness and alter-intentionality or does one's ego-intentionally break the totality apart into several individuals?

One can ask how technological developments incite users to ego- or alterintentionality and how much the individual parts or the totality. As mentioned earlier, technology can be beneficial to create room for the development of emotional transcendence, but it can also create extra hindrances.

People with emotional transcendence-oriented worldviews are strongly aware of the importance of compassion, equanimity, internal experience, emotion, compassion and silence. It is at the basis of a rich internal life. But from within this worldview, it is difficult to provide a justification to solve human problems with technology or focus on the direct experience as we sketched in the immanence worldview. 


\subsection{Libbrecht's Model as Input for VSD in the LED Transition Debate}

The elaborations above enable an overview of the three basic relations and their accompanying underlying assumptions (see Table 10.1). Libbrecht has selected these basic relations as being very different. As a consequence, the fundamentally different underlying assumptions are also difficult to combine. A rational transcendence approach, for example, favours rational insight, control and comfort. Straightforward pathways for including the by-itself-so and the alter-intentionality and mysticity are far from evident. As the intrinsic value of nature, but also emotions, awareness, and compassion might be seen as very important elements, the rational transcendent approach has fundamental difficulties justifying these aspects from within. If one worldview genuinely wants to acknowledge values from the other worldviews, an in-depth dialogue is needed, which will lead to questioning both the other and its own worldview aspects.

The same goes for the VSD application. If the rational transcendence worldview is central in the VSD exercise, values such as well-being, accountability and transparency, democracy and justice, privacy or trust will automatically become central. The values of by-itself-so, alter-intentionality or mysticity will be at least far less prominent, and maybe completely absent in the debate.

This underlines the reason to opt for the Libbrecht model. By considering three fundamental worldviews, it deals with complexity, looking for underlying structures, but it is also manageable. As such, the model itself provides integration and distinguishes itself from a universalism that looks for one main supervalue that unites everyone's main striving. Its description also avoids the over-complexity of pluralism as an irreducible and incommensurable set of different opinions.

This raises a third fundamental question about the usability or limits of the model of Libbrecht. Can the Libbrecht model be accepted and meaningfully used in VSD on LED transitions? Or, differently stated, can the Libbrecht model be used across borders?

\subsection{Discussion}

Throughout this chapter, we encountered three questions that we will further consider here. Can the Libbrecht model be used across borders of different ways of thinking? Can the Value Sensitive Design methodology be used across borders? And, can the value clarification in the LED transition debate be performed across borders? We will discuss the consequences of the interaction between the Libbrecht model, VSD methodology and LED transitions. 


\subsubsection{Libbrecht's Model Across Borders: Consequences of the Plea for Intrinsic Value}

Above, we drew not more than a thumbnail sketch of the whole Libbrecht model. Libbrecht (2007) used 600 dense pages to accurately describe many details and consequences of his model. Suffice to say, the model is able to explain much more than we state here. We are aware that our brief reflection covers may philosophies that also warrant much more precise elaboration. Nevertheless, we can still offer some reflections on, and challenges to, Libbrecht's approach.

Firstly, the question about the comparative merits of the model should be clarified. We argue that the model brings in explicitly new values into the debate. Whereas standard discourse on LEDs focuses on typical transcendent rationalist values such as efficiency and effectiveness, Stone's plea for darkness (2018b) adds qualitative values such as happiness, stellar visibility, and wonder and beauty. And as we have seen above, using the Libbrecht model in VSD brings in fundamentally different values of by-itself-so, non-action, alter-intentionality, awareness and equanimity in the debate on LED. An important question is how, if at all, these values are implicitly embedded in Stone's approach. Does the adoption of Stone's framework require (at least partially) an immanent or a transcendent emotionalist worldview? We will further elaborate this question in Sect. 10.6.3 below.

Secondly, the model is elaborated from a philosophical point of view in the first place, with little explicit elaboration on ethical issues. Thus, the role of ethics and particular values is less elaborated. What is more, the normativity of the three basic worldviews and how this factors into their relations is present but not discussed in detail. The ideal type positions (see Fig. 12.1 in Chap. 12) are clearly not preferable and in themselves very extremist. Too much focus on the direct experience is too bestial. Too much rationality reduces us to a mechanistic view of humans. Too much inner experience risks limiting societal contributions. Instead, in the chapter about happiness and culture (2007: 522-530), Libbrecht mentions that a balanced combination of these three different basic philosophies can contribute to a more harmonious and wholesome human being, culture and world. To the authors of this chapter, this seems a very important normative statement following from the model, even if it is not explicitly formulated. Even if the Libbrecht model is used as a heuristic one, it implicitly prescribes the more fundamental positions that a balance between rationality, immanence and emotional transcendence is needed. Many questions arise. What is the importance of balance? What is a wholesome human being, and what is the role and purpose to be one? How are present-day humans different from wholesome human being? We will discuss the consequences for VSD in Sect. 10.6.2.

Thirdly, the Libbrecht model helps to reflect on the far-reaching assumptions of Stone's plea for taking the intrinsic value of darkness into account. Accepting intrinsic value of nature or mysticism is a non-rational transcendence point of view. Accepting intrinsic value therefore means moving more towards the other two worldviews. It essentially requires us to shift from the central position of human beings in nature $(\mathrm{S} \leftrightarrow \mathrm{O})$, to human beings as a partial element of the surrounding 
world. When people refer to intrinsic values, the subject (S) feels embedded ([Symbol] $)$ in the surroundings or world $(\mathrm{O}=$ object $)$, or the subject feels the fundamental unity of all what is in an $\mathrm{S}=\mathrm{O}$ basic relation.

Starting from the definition of worldview in the Libbrecht model, and from the overview given in Table 10.1, it follows that if a justification uses one element in a particular worldview, it means at least that there will be an inclination to take the other elements from this worldview for granted as well. It is still possible to accept elements from other worldviews, but it is a tougher choice to go against this worldview coherence (See also Oostveen in this volume.). An argumentation from a rational transcendence perspective, for example, will more easily use basic values such as control and comfort, rational knowledge and observation, linear time and binary causality. It will be very difficult to incorporate non-action, direct experience or reticular causality.

As worldview coherence makes accepting one's own worldview elements easier and accepting others more difficult, this also means shifting towards other elements of emotional transcendence or immanence. Accepting intrinsic value therefore means a stronger role of direct and internal experience, values of by-itself-so, nonaction or awareness and equanimity that become more important. The interpretation of Stone's list of values such as efficiency, sustainability, healthiness, happiness, and wonder and beauty will slightly shift. Pertinently, accepting intrinsic value in a VSD process therefore means asking questions differently. The efficiency debate is opened to broader questions, such as how much we wish to question the function and need for 24-h society? Discussions about healthiness will be different from an immanent point of view, accepting life and death or bodily growth and decline, leading in turn to different (less central) positions of safety and security in people's needs. Looking for happiness changes if desire, pleasure and pain are inquired with equanimeous awareness of the emotional transcendence.

\subsubsection{VSD Across Borders: Helping Human Beings and Cultures to Become More Wholesome}

We described how the Libbrecht model puts forward the normative assumption that the ideal type worldviews are less desirable compared to a balanced mix. If we follow this normative assumption that a balanced individual is an individual that incorporates elements from the three worldviews, this could lead to a conclusion that that many people could need more immanence and emotional transcendence. A balanced combination of these three different basic philosophies can contribute to a more wholesome human being and culture. As a consequence, one could argue that the role of VSD then should be to stretch people at least by making them decide about their position towards the three worldviews.

Accepting this point of view necessitates other basic assumptions of VSD. The fourth Habermassian validity claim to the 'rightness and appropriateness of the 
utterance with respect to existing norms and values' (Borning et al. 2005) together with the 'power free dialogue' claim becomes problematic. Whereas the original VSD approach seems to ask for plurality, the Libbrecht model seems to ask for introducing values from other worldviews in the LED debate in order to stretch people's more one-sided worldviews - one could even argue, whether they ask for this or not. The role of a VSD facilitator changes from neutral, transparent, powerfree value facilitation to a critical expert (Bombaerts and Laes 2007; Bombaerts et al. 2006) steering towards other worldviews in order to have a broader view.

The challenge for this procedural view was also analysed by others such as Jacobs and Huldtgren (2018) in a plea to incorporate ethical commitments in VSD. These authors argue to use mid-level ethical approaches consisting of a cluster of pivotal moral principles functioning as general guidelines, such as the capability approach. Of course, inserting 'more transparency' in a design process where transparency is widely acknowledged as an important value seems uncontroversial. The resistance will be limited, non-existing or merely strategic. Inserting by-itselfso, non-action, immediate and intuitive vision of reality, alter-intentionality, awareness or equanimity as elements of a mid-level theory is far more abstract from a rational point of view for people with a mainly rational transcendent worldview. Therefore, it is not entirely obvious how to realise this via technological innovation. How much will people want to sacrifice (perceived) safety and security at night to allow more wonder or visibility of a starry sky? Will the application of the Libbrecht model make things too complex? What about more delicate circumstances such as situations including risks or crisis (Laes et al. 2009; Turcanu et al. 2007)? Some will say that finding a balance between 'Western' or rational transcendent values is already difficult enough and 'broadening' the debate with the Libbrecht model is an unrealistic attempt. In contrast, we believe it is not, and mainly because both the plea for darkness and the Libbrecht model at least try to overcome boundaries that are currently difficult to overcome. This includes the alter-intentionality to put more value to nature than it currently receives in actual LED policy decisions. Including alter-intentionality in VSD will certainly be felt as more far-reaching and will probably be less easily implemented as a mid-level ethical approach in VSD processes. The environmental challenges we currently face seem to require new and more radical ethical models, of which the Libbrecht model could be a contribution.

\subsubsection{LED Transition Debate Across Borders: Further Broadening the Debate}

The Libbrecht analysis of the ontology, epistemology, ethics and view on technology of the three worldviews offers a constructive elucidation of values (and VSD) informing the transition to LED outdoor lighting. The analysis in this chapter allows a reframing of the question of environmental versus social values raised above, instead asserting that they should not be seen in opposition. Rather, they should be 
analysed as part of a greater whole. Tangibly, this would imply that a VSD approach to (smart) LED outdoor lighting should seek to circumvent this question (although perhaps still operating in a largely rationalistic framework) via interventions like incrementally darkening spaces and having environmentally responsive lighting (see Stone 2019 Chap. 5, for an elaboration on these proposals). In both cases, the new technical capabilities of (smart) LEDs would be exploited to foster both the instrumental and intrinsic values of darkness. Yet in doing so, they do not (at least explicitly) confront social values associated with nighttime lighting (safety, nightlife, 24/7 economies, etc.)

Libbrecht's model provides some clarity and grounding for the defining and positioning of (environmental) values in debates about the adoption of LEDs for outdoor lighting. In particular, Stone's approach to darkness seeks to merge, or at least put into dialogue, immanence, transcendent emotionalism and rational transcendence. In this context, appreciating and fostering darkness is about harmony instead of conquering and subjugating nature. It is about (re)discovering a sort of 'dynamic balance' between light and dark, and appreciating the moral significance of such a goal (to use Libbrecht's language). It could also be about finding new attitudes towards 'control' and increasing equanimity and awareness. Achieving a balance, or harmony, between lighting and darkness thus becomes a fundamental underlying goal for LED outdoor lighting. Safety and security at night can be balanced with wonder or visibility of a starry sky if people are prepared to look differently at the role of illumination in providing safety and security, for example.

An interesting question (especially for the context of this book) is then how immanence-oriented ethics $(\mathrm{S} \subset \mathrm{O}$ ) can be inserted into the present-day technological rational transcendence-oriented debate about nighttime lighting. In other words, how do we practically incorporate and appreciate the intrinsic value of darkness? Stone (2018a) elaborates on this idea by exploring notions of the sublime and its relation to experiences of both urban lighting and the night sky. Stone proposes a re-imagined nocturnal sublime that relies in part on ideas from environmental aesthetics that explore the moral significance of sublime experiences. The key idea is that sublime experiences of nature can make possible the conditions for an environmental ethic, as these are experiences that are humbling, and provide a viewpoint of the natural world from which we cannot put ourselves outside or above. The starry night sky, a paradigmatic example of the sublime, can do just that. Thus, there seems to be a possibility of sublime experiences fostering immanence $(\mathrm{S} \subset \mathrm{O})$ relations in Western thought, challenging rational transcendence and our technified, quantified conceptions of environmental sustainability.

\subsection{Conclusion}

In this chapter, we put many things together: the traditional LED debate and one alternative plea for the substantive value of darkness, one example of procedural values with the VSD methodology, and one model of comparative philosophy with 
the Libbrecht model. It goes without saying that bringing together these three ideas, each of which is complex in their own right, was ambitious for a single chapter. However, we deemed it useful in our exploratory approach to show the complexity of applying comparative philosophy in energy policymaking. We are fully aware that the specifications are more or less arbitrary. That is to say that other substantive values could have been discussed, other procedural approaches could have been addressed and other comparative models could have been applied. Nonetheless, we perceive our approach to be a valid and useful one.

The short treatment discussed in this chapter also raised many questions that should be further tackled, especially for ethics and philosophy scholars. Questions are raised with regard to the nature of the relation among the three worldviews, on the one hand, and philosophies such as deep ecology (Naess 1973), social ecology (Bookchin 1988), Buddhism and Daoism, on the other (as currently practised in different parts of the world). Written in English, in a book building a rational argumentation, the Libbrecht model is also strongly embedded in rational transcendentism. Do people—users of a technology—who consider themselves more immanent or transcendent emotionalists feel represented by this model, does the model help them to voice their concerns, or do they still feel limited? For readers unfamiliar with the two other worldviews and their particular epistemological methodologies of direct experience and internal-mystical experience, this model—and a fortiori this short chapter - can only give a glimpse of what is 'on the other side', but it will not give a thorough comprehension needed to incorporate it into VSD for LED transitions. Although, hopefully, through discussing something more familiar (lighting and darkness), we are able to at least give a glimpse into alternative ways of approaching ethical problems.

We applied the Libbrecht model to the VSD methodology for the LED transition debate. In so doing, we described how the set of values in traditional VSD could be broadened to include the value of darkness. We showed how the implicit value of darkness shifts from rational transcendence to more to immanentism or emotional transcendence or to a deepening of the rational transcendence with the intrinsic values defined by Stone (2018b), and in particular via the role of the sublime (2018a). The application also adds to other literature arguing that VSD should further elaborate the normative stance of its methodology. This leads to a fundamental question in how far VSD itself is rooted in rational transcendence. One could argue that, as VSD focuses on clarifying personal values, it risks strengthening instead of weakening people's ego-intentionality. If so, can a more methodological application of the model 'correct' for the specific rational transcendence aspects?

Although we limited ourselves only to the LED policy debate, we draw the hypothesis that our above application can also be useful for other energy innovations. In all cases, both with LED lighting as with other innovations, the ideas presented here should be made more practical with more hands-on application. Further research or actual applications of VSD in energy innovations, such as the LED transition, will be able to more precisely consider how current values (such as safety and security) change, how the concept of the sublime can be helpful and what the role of by-itself-so or alter-intentionality will be. It will also be interesting to see 
how these concretisations will take place in different places of the world. What will the effect be in China, for example, where transcendent emotionalism and immanentism were historically present, but where rational transcendence now seems to be pushed to its limits? How will actual VSD with the Libbrecht model decide on the sensitivity to darkness and on the reduction of the 24-h city? How and how long should the darkness be reduced? What balance of illumination and darkness should we strive for, and why? How will fighting crimes or legitimate nightlife businesses be involved in the process of decision-making, as well as the formulation of the substantive end goals?

Despite the emergence of a seemingly endless list of questions, we hope to have shown that attempting to tackle these is more than relevant. And we hope that our entire exercise in this chapter contributes to the overall goal of the responsible design of outdoor LED lighting and in turn, for other technologies.

Acknowledgements We thank our colleagues (in particular, Andreas Spahn and Sandeep Kesarapu), Daan Oostveen and the reviewers of this chapter for the useful comments.

\section{References}

AMA. (2016). AMA adopts guidance to reduce harm from high intensity street lights. Retrieved September 10, 2016, from www.ama-assn.org/ ama-adopts-guidance-reduce-harm-high-intensity-street-lights

Bombaerts, G., \& Laes, E. (2007). Comparison and analysis of expert and student views on the use of energy scenarios in communication on fusion research. Fusion Engineering and Design, 82(15), 2872-2878.

Bombaerts, G., Bovy, M., \& Laes, E. (2006). RISCOM applied to the Belgian partnership model: More and deeper levels. In VALDOR 2006. Values in decisions on risk. Proceedings (pp. 249-256).

Bookchin, M. (1988). Social ecology versus deep ecology. Socialist Review, 18(3), 9-29.

Borning, A., Friedman, B., Davis, J., \& Lin, P. (2005). Informing public deliberation: Value sensitive Design of Indicators for a large-scale urban simulation. In H. Gellersen, K. Schmidt, M. Beaudouin-Lafon, \& W. Mackay (Eds.), ECSCW 2005 (pp. 449-468). Dordrecht: Springer.

Brey, P. (2015). Design for the value of human well-being. In Handbook of ethics, values, and technological design (pp. 365-382). Berlin: Springer.

Chepesiuk, R. (2009). Missing the dark: Health effects of light pollution. Environmental Health Perspectives, 117(1), 20-27.

Davis, J., \& Nathan, L. P. (2015). Value sensitive design: Applications, adaptations, and critiques. In Handbook of ethics, values, and technological design (pp. 11-40). Dordrecht: Springer. https://doi.org/10.1007/978-94-007-6970-0_3.

De Almeida, A., Santos, B., Paolo, B., \& Quicheron, M. (2014). Solid state lighting reviewPotential and challenges in Europe. Renewable and Sustainable Energy Reviews, 34, 30-48.

Feenberg, A. (2012). Questioning technology. London: Routledge.

Friedman, B., Kahn, P. H., Borning, A., \& Huldtgren, A. (2013). Value sensitive design and information systems. In Early engagement and new technologies: Opening up the laboratory (pp. 55-95). Berlin: Springer.

Gallaway, T., Olsen, R., \& Mitchell, D. (2010). The economics of global light pollution. Ecological Economics, 69, 658-665. 
Hulstijn, J., \& Burgemeestre, B. (2014). Design for the values of accountability and transparency. In Handbook of ethics, values, and technological design (pp. 1-25). Dordrecht: Springer. https://doi.org/10.1007/978-94-007-6994-6_12-1.

International Energy Agency. (2006). Light's labour's lost: Policies for energy-efficient lighting. Paris: OECD/IEA.

Jacobs, N., \& Huldtgren, A. (2018). Why value sensitive design needs ethical commitments. Ethics and Information Technology, 1-4.

Kalupahana, D. J. (1995). Ethics in early buddhism. Honolulu, HI: University of Hawaii Press.

Keates, S. (2015). Design for the value of inclusiveness. In Handbook of ethics, values, and technological design: Sources, theory, values and application domains (pp. 383-402).

Kyba, C. C., Kuester, T., Sanchez de Miguel, A., Baugh, K., Jechow, A., Holker, F., et al. (2017). Artificially lit surface of earth at night increasing in radiance and extent. Science Advances, 3(e1701528), 1-8.

Laes, E., \& Bombaerts, G. (2006). Constructing acceptable Rwm approaches: The politics of participation (No. INIS-US-09-WM-06051). WM Symposia, Inc., PO Box 13023, Tucson, AZ, 85732-3023 (United States). Retrieved from https://www.osti.gov/scitech/biblio/21208573.

Laes, E., Eggermont, G., \& Bombaerts, G. (2009). A risk governance approach for high-level waste in Belgium: A process appraisal. In Managing radioactive Waste' Conference in Göteborg, Sweden.

Libbrecht, U. (2007). Within the four seas...: Introduction to comparative philosophy. Paris; Dudley, MA: Peeters Publishers.

Libbrecht, U. (2009). Comparative Philosophy: A Methodological Approach. In N. Note, R. Fornete-Betancourt, J. Estermann, D. Aerts (Eds.), Worldviews and Cultures. Philosophical Reflections from an Intercultural Perspective. (pp. 31-67). Dordrecht: Springer.

Libbrecht, U., Kimmerle, H., \& Janssens, E. (2016). Filosofie zonder grenzen. Antwerpen/ Apeldoorn: Garant.

Melbin, M. (1987). Night as frontier: Colonizing the world after dark. New York: The Free Press.

Misa, T. J., Brey, P., \& Feenberg, A. (2004). Modernity and technology. Cambridge, MA: MIT Press.

Morgan-Taylor, M. (2014). Regulating light pollution in Europe: Legal challenges and ways forward. In J. Meier, U. Hasenöhrl, K. Krause, \& M. Pottharst (Eds.), Urban lighting, light pollution and society (pp. 159-176). New York: Taylor \& Francis.

Naess, A. (1973). Shallow and deep, long-range ecology movement-Summary. Inquiry-An Interdisciplinary Journal of Philosophy, 16(1), 95-100. https://doi. org/10.1080/00201747308601682.

NAS. (2017). Assessment of solid-state lighting, phase two. Committee on Assessment of SolidState Lighting; Board on Energy and Environmental Systems; Division on Engineering and Physical Sciences; National Academies of Sciences, Engineering, and Medicine. Washington, DC: The National Academies Press.

Nickel, P. J. (2015). Design for the value of trust. In Handbook of ethics, values, and technological design: Sources, theory, values and application domains (pp. 551-567).

Nye, D. E. (1990). Electrifying America: Social meanings of a new technology, 1880-1940. Cambridge: The MIT Press.

O'Keeffe, G. S., \& Clarke-Pearson, K. (2011). Clinical report-The impact of social media on children, adolescents, and families. Pediatrics, 127, 800-804.

Pols, A., \& Spahn, A. (2015). Design for the values of democracy and justice. In Handbook of ethics, values, and technological design: Sources, theory, values and application domains (pp. 335-363).

Royakkers, L., \& Orbons, S. (2015). Design for values in the armed forces: Nonlethal weapons and military robots. In Handbook of ethics, values, and technological design: Sources, theory, values and application domains (pp. 613-638).

Rowe, G., \& Frewer, L. J. (2000). Public participation methods: A framework for evaluation. Science, Technology, \& Human Values, 25(1), 3-29. 
Schivelbusch, W. (1988). Disenchanted night: The industrialization of light in the nineteenth century. (A. Davis, Trans.). London: University of California Press.

Stone, T. (2017). Light pollution: A case study in framing an environmental problem. Ethics, Policy \& Environment, 20(3), 279-293.

Stone, T. (2018a). Re-envisioning the nocturnal sublime: On the ethics and aesthetics of nighttime lighting. Topoi, $1-11$.

Stone, T. (2018b). The value of darkness: A moral framework for urban nighttime lighting. Science and Engineering Ethics, 24(2), 607-628.

Stone, T. (2019). Designing for Darkness: Urban Nighttime Lighting and Environmental Values. Simon Stevin Series in the Ethics and Technology, Vol.16 (ISSN: 1574-941X).

Turcanu, C., Carlé, B., Hardeman, F., Bombaerts, G., \& Van Aeken, K. (2007). Food safety and acceptance of management options after radiological contaminations of the food chain. Food Quality and Preference, 18(8), 1085-1095.

Wang, Q., \& Zhu, Q. (2011). The traditional chinese thinking pattern and its influence upon modern engineering and social development. In S. Christense, C. Mithcam, L. Bocong, \& Y. An (Eds.), Engineering, development, and philosophy: American, Chinese, and European perspectives. Dordrecht: Springer.

Warnier, M., Dechesne, F., \& Brazier, F. (2015). Design for the value of privacy. In Handbook of ethics, values, and technological design: Sources, theory, values and application domains (pp. 431-445).

Yu, X., \& Wang, Q. (2015). Research on the ethics of responsibility from the perspective of comparative philosophy. In W. Qian \& W. Huili (Eds.), Research on practice route of applied ethics in East Asia: Proceedings of the 5th International Conference on Applied Ethics and Applied Philosophy in East Asia (pp. 255-268). Beijing: Science Press.

Open Access This chapter is licensed under the terms of the Creative Commons Attribution 4.0 International License (http://creativecommons.org/licenses/by/4.0/), which permits use, sharing, adaptation, distribution and reproduction in any medium or format, as long as you give appropriate credit to the original author(s) and the source, provide a link to the Creative Commons license and indicate if changes were made.

The images or other third party material in this chapter are included in the chapter's Creative Commons license, unless indicated otherwise in a credit line to the material. If material is not included in the chapter's Creative Commons license and your intended use is not permitted by statutory regulation or exceeds the permitted use, you will need to obtain permission directly from the copyright holder.

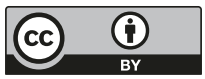

